\title{
O Departamento de Química da Faculdade de Ciências e Tecnologia da Universidade Nova de Lisboa
}

\author{
JOSÉ J. G. MOURA, JORGE LAMPREIA, PEDRO SIMÕES E LÚCIA PEREIRA*
}

O Departamento de Química (DQ) da Faculdade de Ciências e Tecnologia da Universidade Nova de Lisboa, embora relativamente recente (criado em 1981), tem já uma reconhecida implementação no mercado de ensino e de trabalho, em particular devido à então novidade e especificidade introduzida pela Licenciatura em Química Aplicada, com a qual se iniciou o ensino da Química na Faculdade. Desde há três anos o Departamento atingiu uma nova dimensão pelo facto de se ter concluído um novo edifício departamental de dimensões adequadas permitindo instalar, de um modo condigno, os Departamentos de Química e de Ambiente assim como as Secções Autónomas de Biotecnologia e Grupo de Disciplinas de Ecologia da Hidrosfera.

O Departamento de Química (que engloba o Centro de Química Fina e Biotecnologia) tem um corpo docente que compreende 46 doutorados e 8 não doutorados, incluindo ainda 24 bolseiros.

Em termos de espaço, e em virtude da actual situação de congelamento de contratação de docentes, o DQ atingiu um estado estacionário, que permite um ratio espaço de investigação/docência adequado e aceitável.

\section{ESTRUTURA DO DQ}

O Departamento de Química da FCT/UNL constitui uma unidade orgânica permanente da Faculdade de Ciências e Tecnologia da Universidade Nova de Lisboa, vocacionado para o ensino, a investigação científica e prestação de serviços em áreas da Química, da Bioquímica e da Engenharia Química com as finalidades gerais previstas na lei e nos estatutos da FCT.

O Departamento integra quatro Secções: Química-Física e Inorgânica, Química Orgânica, Engenharia Química e Bioquímica e um Centro de Investigação (Centro de Química Fina e Biotecnologia (CQFB) da FCT/UNL) cabendo-lhe o papel de promover e harmonizar a investiga- ção interdisciplinar no âmbito do Departamento.

O Conselho do Departamento (CD), com a sua Comissão Coordenadora e a Comissão Executiva, tem competências bem definidas em regulamento. Este Conselho é constituído pelos doutores, como membros permanentes, e por membros não permanentes eleitos de entre os restantes docentes e investigadores, de cada Secção, não excedendo o seu número em um por Secção. A Comissão Coordenadora, integra o Presidente e um Professor Catedrático ou Associado, por cada Secção, eleito pelos membros da mesma e tem as competências que lhe forem delegadas pelos conselho de Departamento.

O Centro de Química Fina e Biotecnologia (CQFB), com regulamento próprio, é uma unidade de investigação criada junto do Departamento de Química da FCT/UNL (apoiada inicialmente pelo Programa Ciência e Contrato Plurianual com a JNICT). É, actualmente, constituído pelas seguintes áreas de investigação:

A- Síntese Selectiva e Química Estrutural

B- Química Bio-Orgânica e Analítica

C - Química de Produtos Naturais e Síntese Orgânica

D - Termodinâmica e Processos de Separação

E - Química Bio-Inorgânica e Engenharia de Proteínas

F - Fotoquímica e Química Supramolecular

G - Engenharia de Reacções em Química Fina

H - Engenharia Bioquímica e de Processos

I - Bioquímica-Física de Proteínas

$\mathrm{J}$ - Aspectos Bioquímicos e Biofísicos do Transporte Biológico

As Comissões Pedagógicas das licenciaturas ministradas pelo departamento têm como missão gerir a relação entre o corpo discente e docente, estando atentas às necessidades pedagógicas e de formação, propondo alterações curriculares genéricas e pugnando para que, em cada momento, os estudantes recebam o melhor curso possível, dadas as circuns- tâncias. São compostas por dois doutorados, dois não-doutorados e quatro estudantes das respectivas licenciaturas. A Comissão Pedagógica da Licenciatura em Química Aplicada tem, ainda, um membro doutorado pertencente à Secção Autónoma de Biotecnologia, efectivamente envolvido no Ramo de Biotecnologia desta licenciatura.

\section{Biblioteca Departamental}

A FCT tem uma Biblioteca Central situada no campus do Monte de Caparica coordenada por um Director e Coordenadora Bibliotecária. Esta Biblioteca encontra-se agora em fase de expansão com a criação de extensões, regidas pelo regulamento da Biblioteca Central e que vão permitir aumentar o espaço de arquivo e de salas de leitura e consulta. Uma destas extensões situa-se no Edifício Departamental servindo as áreas de Química, Ambiente e Biotecnologia. Segue-se a criação das extensões nas áreas de Informática e Matemática.

Em particular, a extensão existente no Edifício Departamental está numa fase de informatização e o seu espólio foi, recentemente, muito enriquecido pela doação de parte das existências da Biblioteca da Quimigal, agora integradas com os periódicos que cobrem os interesses da Química, Ambiente e Biotecnologia. Um esforço está a ser desenvolvido no sentido de, numa fase posterior, ser possível o acesso a bases de dados internas e exteriores. A Biblioteca é também utilizada para exposições temporárias bibliográficas exteriores à Faculdade.

\section{ENSINO NO DQ}

O DQ tem a seu cargo a responsabilidade de gerir as Licenciaturas de Química Aplicada e Engenharia Química.

No seu início, a Universidade Nova de Lisboa e, consequentemente, as Faculdades que lhe iriam pertencer, estava pensada para ser um campus com uma grande interacção entre as diversas áreas/Faculdades 
existentes. Os alunos poderiam frequentar um curso determinado e, como em alguns países, ter disciplinas noutras áreas do saber. Este plano nunca foi efectivamente concretizado, por vicissitudes várias, mas esta interdisciplinaridade, bem como o seu sistema de créditos, ainda se reflectem hoje na organização dos dois cursos ministrados pelo Departamento de Química.

Os alunos do DQ dispõem da possibilidade de solicitar Aconselhamento Pedagógico se tal desejarem. O Aconselhamento aos alunos é prestado por quatro professores do departamento, sendo dois deles os Presidentes das Comissões Pedagógicas das Licenciaturas, com a função de esclarecer dúvidas postas pelos alunos sobre o conteúdo curricular das disciplinas, articulação entre elas e sua importância na formação escolar e profissional dos alunos. Este modelo de aconselhamento é facul-

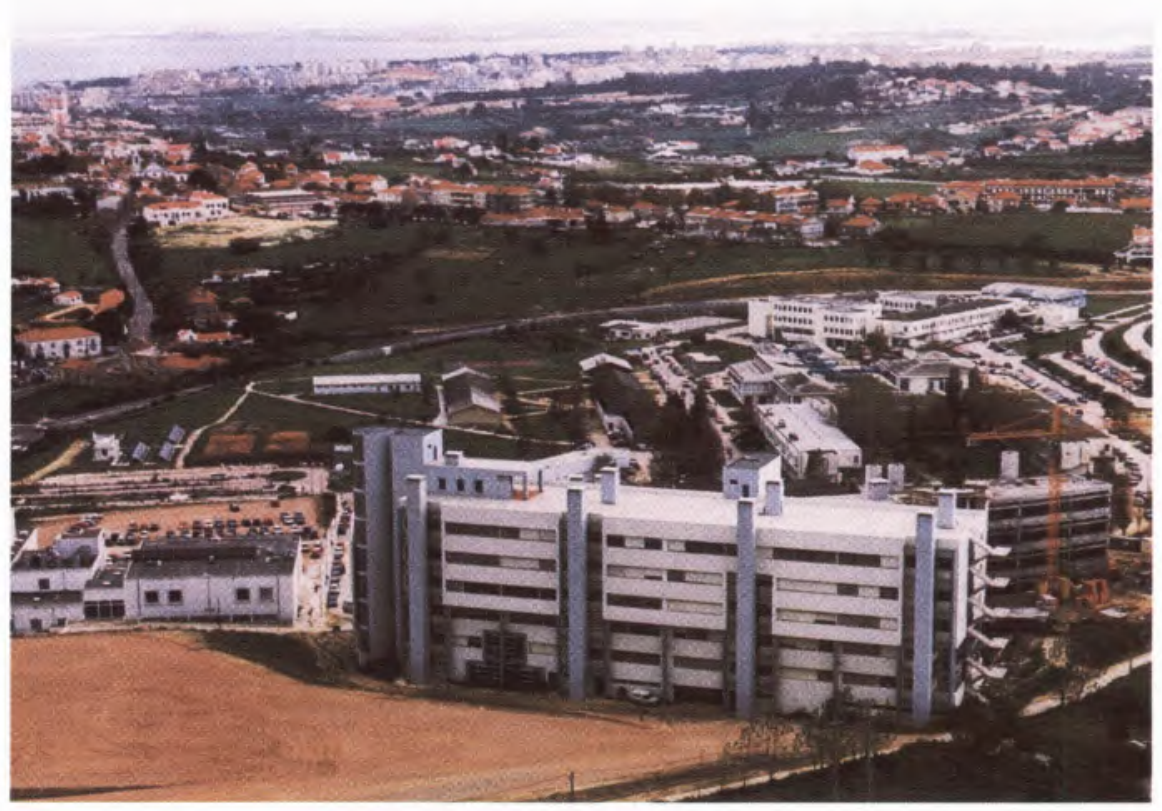

tativo, devendo ser solicitado pelos alunos interessados.

\section{Organização da Licenciatura em Química Aplicada}

A licenciatura está, como já foi dito, dividida em Tronco Comum e Ramos que se passam a descrever.

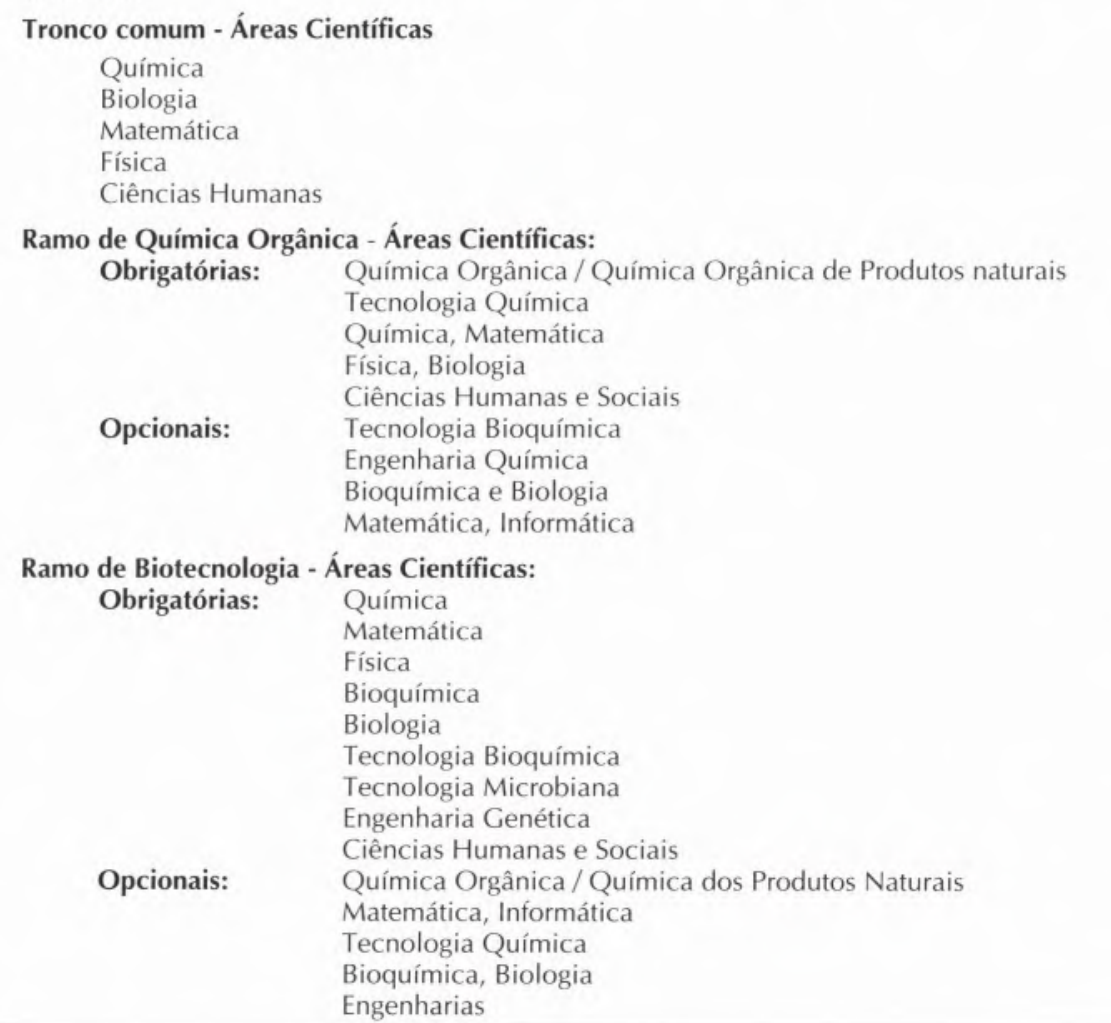

\section{- Licenciatura em Química Aplicada}

A Licenciatura em Química Aplicada surgiu em $81 / 82$ como reflexo da necessidade de se complementar a formação clássica em Química, Biologia e Bioquímica, abordando aspectos inovadores no domínio da Química Orgânica e Biotecnologia. Estas eram e são áreas de ponta, o que continua a justificar uma orientação privilegiada dos licenciados para o campo de investigação sem, contudo, deixar de ser conjugada com uma boa integração na indústria. A licenciatura está, assim, organizada em três anos de formação básica que conduzem a dois ramos de especialização, com a duração de dois anos.

O perfil do curso dá um grande ênfase à componente laboratorial e aposta fortemente na interdisciplinaridade entre as diversas áreas científicas.

Através de um esforço empenhado que vem sendo desenvolvido desde o início da licenciatura é possível, actualmente, ter à disposição dos alunos um conjunto de material de laboratório, instrumentação vária e espaço físico que possibilita a execução efectiva, por parte dos alunos, de Aulas Práticas de Laboratório. No novo edifício que ocupamos, estas podem ter, excepcionalmente, até aos oito grupos por sessão - 24 alunos, 
sendo seis grupos o mais habitual, até ao $3^{\circ}$ ano da licenciatura. Nas cadeiras dos Ramos a organização é, obviamente, diferente e mais particular.

Neste momento o numerus clausus para a Licenciatura estabilizou e é de 60 alunos.

A Licenciatura de Química Aplicada é um curso vocacionado para a investigação e indústria em áreas inovadoras tais como:

Indústria de Fermentação Química Fina (Sínteses)

Indústria Farmacêutica

Indústria Alimentar

Indústria de Perfumaria

Processos Separativos

Engenharia Genética

Tecnologia Enzimática

Tecnologia Ambiental

\section{Saídas Profissionais:}

A licenciatura está pensada em termos de saídas profissionais nas áreas das Indústrias de Sector Químico, Biotecnológico e afins (Indústrias Fermentativas, Alimentares, Farmacêuticas, Agroquímicas, Cosmética), Serviços Públicos, Laboratórios de Análises, Controlo de Qualidade, Empresa de Consultadoria, Ensino e Investigação.

\section{Ensino - Licenciatura}

O ensino da área da Química aplicada na FCT-UNL, com dois ramos diversificados, permitiu dar uma personalidade forte ao ensino da Química na FCT, imediatamente reconhecida no exterior. Estes tópicos são complexos e têm uma forte componente interdisciplinar. Assim, o curso foi desenhado no sentido de permitir flexibilidade, introduzindo cadeiras de opção adequadas e sempre baseado num sistema de créditos o que permite, dentro do possível uma licenciatura mais "por medida" que por "pret-à-porter".

Nos três primeiros anos é fornecida informação básica nas áreas da Química (Inorgânica, Analítica e Química-Física), Física, Matemática, sendo introduzidos conceitos de Bioquímica e Biologia. É de realçar a utilização efectiva de equipamento analítico e instrumental (potenciómetros, condutímetros, espectrofotómetros UV-vísivel, infravermelhos, magnetoquímica, cromatografias e técnicas electroquímicas várias). A partir do $4^{\circ}$ ano os alunos podem optar pelos ramos de Química Orgânica e Biotecnologia. O ramo de Química Orgânica proporciona aos alunos uma formação básica em síntese orgânica, mecanismos reaccionais, análise estrutural, com forte implicação na área dos produtos naturais. O Ramo de Biotecnologia está vocacionada para as áreas múltiplas da biologia molecular, tecnologia de enzimas, reactores biotecnológicos e informação nas áreas de processos relacionados com as bio-indústrias. Nestes dois últimos anos os alunos ingressam em tópicos mais especializados e dirigidos, em que técnicas sofisticadas da área da biologia molecular são correntemente utilizadas e métodos estruturais são aplicados como ressonância paramagnética electrónica (RPE) e ressonância magnética nuclear (RMN). No último ano os alunos podem optar pela realização de estágio curricular (em adição a cadeiras do $10^{\circ}$ Semestre) que lhes permite um contacto real com um grupo de investigação ou uma indústria. Tem sido encorajada, pela Comissão Pedagógica da LQA, a saída dos alunos da FCT para outras unidades exteriores de investigação ou industriais permitindo não só o contacto com o mundo exterior mas também que esse mundo possa reconhecer as competências dos alunos formados no DQ/FCT/UNL.

\section{- Licenciatura em Engenharia Química}

A formação de licenciados com perfil de Engenheiro Químico iniciou-se na FCT/UNL em 1977 como Ramo de Processos Químicos da licenciatura de Engenharia de Produção Industrial, mais tarde alterado para Ramo de Engenharia Química (1984). Finalmente, em 1986, iniciou-se a licenciatura em Engenharia Química como licenciatura autóno- ma integrando desde logo os alunos desde o $\mathrm{I}^{\circ}$ ano.

A licenciatura em Engenharia Química da FCT/UNL tem uma estrutura curricular própria que a diferencia de outras licenciaturas em Engenharia Química oferecidas no País. Mantém uma sólida formação em Matemática (6 semestres lectivos) e Física (2 semestres lectivos, além de Química-Física e Termodinâmica Química), apresentando contudo um menor número de disciplinas de Química (10 semestres lectivos) do que outras escolas de engenharia. Pretende-se oferecer uma boa formação em Química, mais forte do que é tradicional em cursos de escola Anglo-Saxónica, mas cultivando desde o início uma "cultura" de Engenharia Química. Inovadora é a combinação, existente desde o início, com a formação em Gestão, através de um conjunto significativo de disciplinas obrigatórias na área da gestão industrial e planeamento ( 5 semestres lectivos) e de disciplinas de opção (3 semestres lectivos).

O curriculum escolar está organizado de uma forma que reflecte a preocupação numa boa formação interdisciplinar. O número de disciplinas leccionado por outros departamentos é elevado e os alunos podem realizar as suas disciplinas de Opção frequentando qualquer disciplina oferecida pela Universidade Nova de Lisboa (até ao máximo de 7 unidades de crédito). De igual modo tem sido estimulada a participação dos alunos no Programa ERASMUS, o qual lhes permite a realização de estágios no estrangeiro e o contacto com realidades diferentes do meio escolar.

A licenciatura integra no último ano a disciplina de Projecto (2 semestres lectivos) a qual permite aos alunos utilizar os seus conhecimentos de uma forma integrada estudando o processo de fabrico e comercialização de um produto, desde as fases de análise de mercado, dimensionamento e instrumentação da instalação, e estudo de viabilidade económica. 
Por forma a complementar os objectivos anteriores a secção de Eng. ${ }^{a}$ Química dispõe recentemente de uma unidade piloto, constituída por um reactor químico de $1 \mathrm{~m}^{3}$ de capacidade (tipo tanque com agitação), uma torre de destilação e respectiva torre de refrigeração, caldeira eléctrica e permutador de calor. É de realçar que todo o equipamento é controlado por uma unidade de controle ligado a um computador. Desde modo, os alunos podem efectuar aulas práticas realizando testes de produção em regime piloto.

Com o objectivo de preparar os alunos para a sua futura inserção no mercado de trabalho, tem sido dedicada uma particular atenção à realização de visitas de estudo a diferentes unidades industriais. Pretende-se que os alunos adquiram conhecimentos relevantes para as disciplinas em que essas visitas são inseridas (caso das disciplinas de Indústrias Químicas, Bioenergética Industrial, Tecnologia de Enzimas) e que se apercebam de quais as funções que o Engenheiro Químico desempenha nessas unidades, quais as suas responsabilidades, e quais as perspectivas de carreira que se abrem após a conclusão da sua formação académica. Por esta razão, o corpo docente da Secção de Engenharia Química integra vários docentes convidados que mantêm actividade empresarial ou integram o quadro de empresas, os quais leccionam diferentes disciplinas do $4^{\circ}$ e do $5^{\circ}$ ano da Licenciatura, tais como Indústrias Químicas, Tecnologia de Plásticos e Projecto AA, permitindo aos alunos o contacto com docentes com outro tipo de experiência profissional.

\section{Organização da Licenciatura}

A estrutura da licenciatura engloba as seguintes áreas científicas (entre parêntesis é indicado o número de créditos necessários serem obtidos em cada uma dessas áreas, sendo o número total necessário à concessão do grau de Engenheiro de 154):

\begin{tabular}{lr} 
Áreas Científicas Obrigatórias: & \\
\hline Biotecnologia & (7 créditos) \\
Ciências Humanas e Sociais & ( 2 créditos) \\
Engenharia Industrial & $(11$ créditos) \\
Engenharia Química & $(44$ créditos) \\
Física & ( 8 créditos) \\
Matemática & $(23$ créditos) \\
Informática & $(6$ créditos) \\
Matérias Interdisciplinares & $(10$ créditos) \\
Química & $(28$ créditos)
\end{tabular}

Áreas Científicas Optativas (15 créditos): Biotecnologia/Agroindústria Engenharia Industrial

Química

Tecnologia e Utilidades

Ambiente

(Nota: até ao limite de 7 unidades de crédito os alunos poderão efectuar qualquer disciplina cursada na Universidade Nova de Lisboa)

O curso de Engenharia Química assegura uma formação para o desempenho de funções nomeadamente de:

- Concepção e desenvolvimento de novos processos

- Projecto industrial

- Planeamento, optimização e controlo da produção

- Controlo da qualidade e controlo da poluição

- Manutenção e gestão de stocks

- Automação e segurança

- Direcção de produção

- Direcção fabril

\section{Áreas potenciais de emprego:}

- Indústrias de Sector Químico e afins:

* Produtos Químicos, Ácidos, Adubos, Papel, Pesticidas, etc.

* Transformação de Plásticos, Resinas, Tintas e Vernizes.

* Química Orgânica, Orgânica Fina e Bioquímica.

* Petroquímica e Refinação de Petróleos

- Serviços Públicos e Empresas de Serviços

- Gabinetes de Estudos e Projectos de Engenharia

- Laboratórios de Engenharia e de Investigação nas Empresas

- Docência e Investigação no Ensino Superior

\section{Ensino - Licenciatura}

Nos dois primeiros anos da licenciatura de Engenharia Química é fornecida aos alunos uma formação básica nas áreas da Química (Inorgânica, Orgânica e Termodinâmica), Física e Matemática (Análise Matemática, Álgebra e Estatística). No $3^{\circ}$ semestre os alunos podem optar pela realização de cadeiras de índole analítica (Química Analítica I e Métodos Instrumentais de Análise I) que lhes proporciona o conhecimento e utilização de diversas técnicas de análise correntes. No $4^{\circ}$ semestre, os estudantes têm a sua primeira introdução à temática de engenharia química através da cadeira de Fundamentos dos Processos Químicos (os alunos adquirem formação básica na quantificação dos processos de fabrico através da realização de balanços de massa e de energia). Nos $3^{\circ}$ e $4^{\circ}$ anos do curso é dado grande ênfase ao estudo das ciências de engenharia (cadeiras de Fenómenos de Transferência e Transferência de Massa e Processos de Separação); são estudados diversos processos de separação (cadeiras de Operações Sólido-Fluido, Processos de Separação I e II), e os conceitos associados a processos envolvendo reacções químicas (cadeiras de Reactores Químicos), assim como são fornecidas bases na área do planeamento e controlo desses processos. No último ano do curso, e através de uma alteração curricular efectuada recentemente, pretende-se que o aluno tenha um número o mais reduzido possível de disciplinas. A intenção é a de os alunos se concentrarem nas cadeiras de Projecto AA (2 semestres) e Laboratórios I. A cadeira de Projecto constitui o culminar de toda a aprendizagem adquirida pelo aluno ao longo do curso através da sua utilização na realização de um ante-projecto de uma unidade fabril. A disciplina de Laboratórios I tem como objectivo a introdução dos alunos à investigação científica, através da realização de um trabalho de investigação original de pequena dimensão, sob a orientação de um professor da secção de Engenharia Química. Na medida do 
possível, os alunos são incentivados a realizar projectos que apresentem colaboração com outros laboratórios, nacionais ou estrangeiros.

Número de Vagas actual: 40 alunos

\section{PÓS-GRADUAÇÃo}

O Departamento de Química organiza, bianualmente, um Mestrado em Química Orgânica Tecnológica no qual estão envolvidos os docentes residentes desta área assim como um apreciável número de professores e investigadores estrangeiros e nacionais de outras Instituições.

\section{INVESTIGAÇÃO}

A investigação levada a cabo pelo Departamento de Química é uma actividade com grande impacto no campo científico quer pela diversidade quer pela qualidade do trabalho desenvolvido, facilmente observável pelo número de trabalhos científicos publicados em revistas nacionais $\mathrm{e}$ intercionais. As grandes áreas de investigação existentes são, genericamente, aquelas descritas anteriormente no ponto referente ao Centro de Química Fina e Biotecnologia.

* Departamento de Química e Centro de Química Fina e Biotecnologia, Faculdade de Ciências e Tecnologia, Universidade Nova de Lisboa,

2825 Monte da Caparica

http://www.dq.fct.unl.pt/

Plano Curricular aconselhado da Licenciatura em Química Aplicada Tronco Comum - Disciplinas para 1997/98

\begin{tabular}{|c|c|c|c|c|c|}
\hline \multicolumn{6}{|c|}{$1^{\circ}$ Semestre } \\
\hline \multicolumn{6}{|c|}{ Horas/semana } \\
\hline Disciplina & $\mathbf{T}$ & TP & $\mathbf{P}$ & U.C. & A. C. \\
\hline Álgebra Linear e Geometria Analítica & 3 & 0 & 3 & 4 & Matemática \\
\hline Análise Matemática I & 3 & 0 & 3 & 4 & Matemática \\
\hline Introdução à Química Física & 2 & 1 & 1.5 & 3 & Química \\
\hline Técnicas de Laboratório & 1 & 1 & 3 & 3 & Química \\
\hline Teoria da Ligação Química & 2 & 2 & 0 & 3.5 & Química \\
\hline Opção de C.H.S. (Opcional) & & & & & C.H.S. \\
\hline \multicolumn{6}{|c|}{$2^{\circ}$ Semestre } \\
\hline Disciplina & $\mathbf{T}$ & TP & $\mathbf{P}$ & U.C. & A. C. \\
\hline Química Inorgânica I & 2 & 1 & 2 & 3.5 & Química \\
\hline Análise Matemática II & 3 & 0 & 3 & 4 & Matemática \\
\hline Introdução Computadores e Program. (Opcional) & 2 & 0 & 2 & 3 & Informática \\
\hline Física I & 3 & 0 & 3 & 4 & Física \\
\hline Química Orgânica AA & 2 & 0 & 4 & 3.5 & Química \\
\hline Opção C. H. S. (Opcional) & & & & & C. H.S. \\
\hline \multicolumn{6}{|c|}{$3^{\circ}$ Semestre } \\
\hline Disciplina & $\mathbf{T}$ & TP & $\mathbf{P}$ & U.C. & A. C. \\
\hline Probabilidades e Estatística B & 3 & 0 & 3 & 4 & Matemática \\
\hline Física III & 3 & 0 & 3 & 4 & Física \\
\hline Análise Matemática III (Opcional) & 3 & 0 & 3 & 4 & Matemática \\
\hline Química Analítica I & 2 & 1 & 2 & 3.5 & Química \\
\hline Química Orgânica AA & 2 & 0 & 4 & 3.5 & Química \\
\hline Opção C. H. S. (Opcional) & & & & & C. H.S. \\
\hline \multicolumn{6}{|c|}{$4^{\circ}$ Semestre } \\
\hline Disciplina & $\mathbf{T}$ & TP & $\mathbf{P}$ & U.C. & A. C. \\
\hline Fundamentos dos Processos Químicos & 2 & 0 & 3 & 3 & Tec. Qui. \\
\hline Termodinâmica Química & 3 & 2 & 0 & 4.5 & Química \\
\hline Química Analítica II & 2 & 1 & 2 & 3.5 & Química \\
\hline Bioquímica I & 2 & 0 & 4 & 3.5 & Biologia \\
\hline Química Inorgânica II & 2 & 0 & 3 & 3 & Química \\
\hline Análise matemática IV (Opcional) & 3 & 0 & 3 & 4 & Matemática \\
\hline Computação (Opcional) & 2 & 0 & 3 & 3 & Informática \\
\hline Opção de C. H. S. (Opcional) & & & & & C. H.S. \\
\hline
\end{tabular}




\begin{tabular}{|c|c|c|c|c|c|}
\hline \multicolumn{6}{|c|}{$5^{\circ}$ Semestre } \\
\hline $\begin{array}{l}\text { Disciplina } \\
\text { Bioquímica II } \\
\text { Métodos Instrumentais de Análise I } \\
\text { Química Física I } \\
\text { Química de Produtos Naturais I }\end{array}$ & $\begin{array}{l}\mathbf{T} \\
2 \\
2 \\
2 \\
2\end{array}$ & $\begin{array}{l}\text { TP } \\
0 \\
0 \\
1 \\
0\end{array}$ & $\begin{array}{l}\mathbf{P} \\
4 \\
3 \\
2 \\
4\end{array}$ & $\begin{array}{l}\text { U. C. } \\
3.5 \\
3 \\
3.5 \\
3.5\end{array}$ & $\begin{array}{l}\text { A. C. } \\
\text { Biologia } \\
\text { Química } \\
\text { Química } \\
\text { Química }\end{array}$ \\
\hline \multicolumn{6}{|c|}{$6^{\circ}$ Semestre } \\
\hline $\begin{array}{l}\text { Disciplina } \\
\text { Métodos Instrumentais de Análise II } \\
\text { Biologia Molecular } \\
\text { Mecanismos das Reacções Químicas } \\
\text { Microbiologia } \\
\text { Química Física II }\end{array}$ & $\begin{array}{l}\mathbf{T} \\
2 \\
2 \\
2 \\
2 \\
2\end{array}$ & $\begin{array}{c}\text { TP } \\
0 \\
0 \\
2 \\
0 \\
1\end{array}$ & $\begin{array}{l}\mathbf{P} \\
3 \\
4 \\
2 \\
4 \\
2\end{array}$ & $\begin{array}{c}\text { U. C. } \\
3 \\
3.5 \\
4 \\
3.5 \\
3.5\end{array}$ & $\begin{array}{l}\text { A. C. } \\
\text { Química } \\
\text { Biologia } \\
\text { Química } \\
\text { Biologia } \\
\text { Química }\end{array}$ \\
\hline \multicolumn{6}{|c|}{$\begin{array}{c}\text { Ramo Biotecnologia } \\
7^{9} \text { Semestre }\end{array}$} \\
\hline $\begin{array}{l}\text { Disciplina } \\
\text { Genética Molecular I } \\
\text { Bioquímica Analítica I } \\
\text { Bioenergética Celular I } \\
\text { Tecnologia Microbiana }\end{array}$ & $\begin{array}{l}\mathbf{T} \\
2 \\
2 \\
2 \\
2\end{array}$ & $\begin{array}{c}\text { TP } \\
0 \\
0 \\
0 \\
0\end{array}$ & $\begin{array}{l}\mathbf{P} \\
4 \\
4 \\
4 \\
4\end{array}$ & $\begin{array}{l}\text { U. C. } \\
3.5 \\
3.5 \\
3.5 \\
3.5\end{array}$ & $\begin{array}{l}\text { A. C. } \\
\text { Eng. Gen. } \\
\text { Tec. Bioq. } \\
\text { Tec. Bioq. } \\
\text { Tec. Mic }\end{array}$ \\
\hline \multicolumn{6}{|c|}{$8^{\circ}$ Semestre } \\
\hline $\begin{array}{l}\text { Disciplina } \\
\text { Engenharia Genética I } \\
\text { Engenharia Genética II2 } \\
\text { Genética Molecular II } \\
\text { Fotossíntese e Produção Primária }\end{array}$ & $\begin{array}{l}\mathbf{T} \\
2 \\
0 \\
2 \\
2\end{array}$ & $\begin{array}{c}\text { TP } \\
0 \\
4 \\
0 \\
0\end{array}$ & $\begin{array}{c}\mathbf{P} \\
4 \\
3.5 \\
4 \\
4\end{array}$ & $\begin{array}{l}\text { U. C. } \\
\text { 3.5 } \\
\text { Eng. Gen. } \\
\text { 3.5 } \\
3.5\end{array}$ & $\begin{array}{l}\text { A. C. } \\
\text { Eng. Gen. } \\
\text { Eng. Gen. } \\
\text { Tec. Bioq. }\end{array}$ \\
\hline \multicolumn{6}{|c|}{$9^{\circ}$ Semestre } \\
\hline $\begin{array}{l}\text { Disciplina } \\
\text { Engenharia Bioquímica } \\
\text { Microbiologia Alimentar } \\
\text { Microbiologia Industrial } \\
\text { Opções }\end{array}$ & $\begin{array}{l}\mathbf{T} \\
2 \\
2 \\
2\end{array}$ & $\begin{array}{l}\text { TP } \\
0 \\
0 \\
0\end{array}$ & $\begin{array}{l}\mathbf{P} \\
4 \\
4 \\
4\end{array}$ & $\begin{array}{l}\text { U. C. } \\
3.5 \\
3.5 \\
3.5\end{array}$ & $\begin{array}{l}\text { A. C. } \\
\text { Tec.Bioq. } \\
\text { Tec. Mic. } \\
\text { Tec. Mic. }\end{array}$ \\
\hline
\end{tabular}

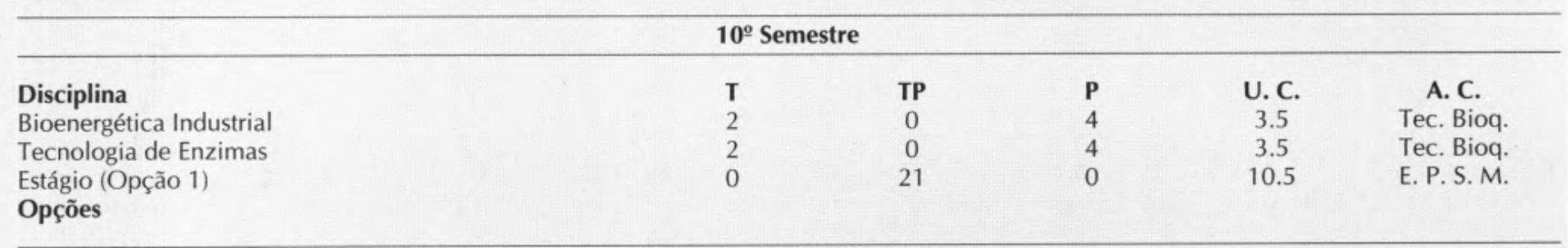

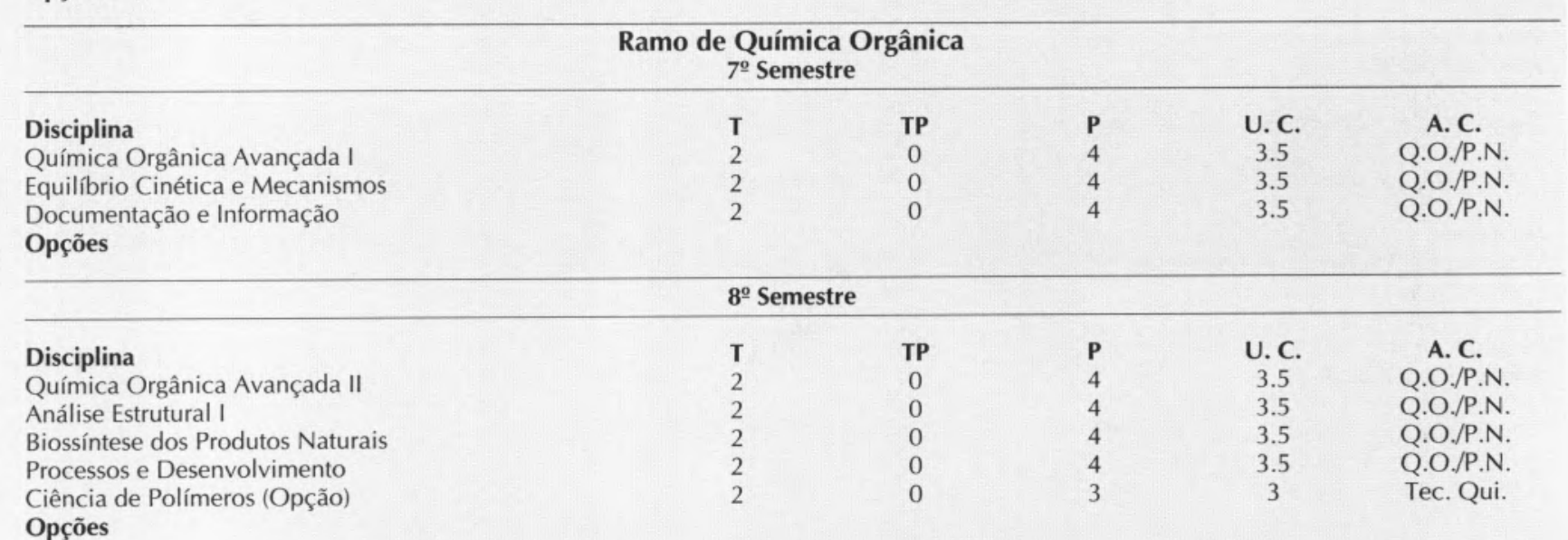




\begin{tabular}{|c|c|c|c|c|c|}
\hline \multicolumn{6}{|c|}{$9^{\circ}$ Semestre } \\
\hline Disciplina & $\mathbf{T}$ & TP & $\mathbf{P}$ & U.C. & A. C. \\
\hline Química dos Produtos Naturais II & 2 & 0 & 4 & 3.5 & Q.O./P.N. \\
\hline Análise Estrutural II & 2 & 0 & 4 & 3.5 & Q.O./P.N. \\
\hline $\begin{array}{l}\text { Síntese Orgânica I } \\
\text { Opcões }\end{array}$ & 2 & 0 & 4 & 3.5 & Q.O./P.N. \\
\hline
\end{tabular}

\begin{tabular}{llcccc}
\hline & $\mathbf{1 0}^{\mathbf{0}}$ Semestre & & & U. C. & A. C. \\
\hline Disciplina & T & TP & P & Q.O./P.N. \\
Química dos Produtos Naturais III & 2 & 0 & 4 & 3.5 & Q.O./P.N. \\
Síntese Orgânica II & 2 & 0 & 4 & 3.5 & E. P.S.M. \\
Estágio (Opção 1) & 0 & 21 & 0 & 10.5 & E.
\end{tabular}

\section{Opções Existentes *}

\begin{tabular}{|c|c|c|c|c|c|}
\hline Disciplina & $\mathbf{T}$ & TP & $\mathbf{P}$ & U.C. & A.C. \\
\hline Inglês I (I) & 0 & 2 & 0 & 1.5 & C. H.S. \\
\hline Inglês II (P) & 0 & 2 & 0 & 1.5 & C. H.S. \\
\hline Aspectos do Pensamento Contemporâneo (P) & 4 & 0 & 0 & 4 & C. H.S. \\
\hline Aspectos do Pensamento Contemporâneo (I) & 2 & 0 & 0 & 2 & C. H.S. \\
\hline Economia I (I) & 3 & 0 & 3 & 4 & C. H.S. \\
\hline Economia II (P) & 3 & 0 & 3 & 4 & C. H.S. \\
\hline História da Ciência (I) & 2 & 0 & 0 & 2 & C. H. S. \\
\hline História das Ideias em Química (P) & 2 & 0 & 0 & 2 & C. H.S. \\
\hline Psicologia Educacional (I) & 4 & 0 & 2 & 5 & C. H.S. \\
\hline Sociologia da Educação (P) & 4 & 0 & 2 & 5 & C. H.S. \\
\hline Sociologia Industrial (I) & 2 & 0 & 2 & 3 & C. H.S. \\
\hline Física Atómica e Molecular (P) & 3 & 0 & 3 & 4 & Física \\
\hline Bioquímica Ecológica (I) & 2 & 0 & 4 & 3.5 & Biologia \\
\hline Bio-Segurança e Bio-Ética & 2 & 2 & 0 & 3.5 & Biologia \\
\hline Bioenergética Celular I (I) & 2 & 0 & 4 & 3.5 & Tec. Bioq. \\
\hline Bioenergética Celular II (P) & 2 & 0 & 4 & 3.5 & Tec. Bioq. \\
\hline Bioenergética Industrial $(\mathrm{P})$ & 2 & 0 & 4 & 3.5 & Tec. Bioq. \\
\hline Biofísica Inorgânica (P) & 2 & 0 & 4 & 3.5 & Tec. Bioq. \\
\hline Bioquímica Analítica I (I) & 2 & 0 & 4 & 3.5 & Tec. Bioq. \\
\hline Bioquímica Analítica II (P) & 2 & 0 & 4 & 3.5 & Tec. Bioq. \\
\hline Fotoquímica (P) & 2 & 0 & 4 & 3.5 & Química \\
\hline Técnicas Cromatográficas (I) & 2 & 0 & 4 & 3.5 & Química \\
\hline Química Orgânica Industrial (I) & 2 & 0 & 4 & 3.5 & Química \\
\hline Biossíntese na Industria Química (P) & 2 & 0 & 4 & 3.5 & Química \\
\hline Controlo da Qualidade (I) & 2 & 0 & 4 & 3.5 & Química \\
\hline Química na Industria e Sociedade (P) & 3 & 0 & 0 & 3 & Química \\
\hline Reactores Químicos I (I) & 2 & 0 & 3 & 3 & Tec. Qui. \\
\hline Transferência de Massa Process.Separação (P) & 2 & 0 & 3 & 3 & Tec. Qui. \\
\hline Indústrias Químicas (I) & 3 & 0 & 0 & 3 & Tec. Qui. \\
\hline Projecto $\mathrm{AA}(\mathrm{I}+\mathrm{P})$ & 0 & 6 & 8 & 7 & Tec. Qui. \\
\hline Petroquímica $(\mathrm{P})$ & 2 & 0 & 3 & 3 & Tec. Qui. \\
\hline Ciência de Polímeros (P) & 2 & 0 & 3 & 3 & Tec. Qui. \\
\hline Estágio I (I) & 0 & 105 & 0 & 3.5 & . \\
\hline Estágio II (P) & 0 & 105 & 0 & 3.5 & . \\
\hline Estágio & 0 & 315 & 0 & 10.5 & . \\
\hline
\end{tabular}

Nas Cadeiras de Estágio I, II e Estágio as horas indicadas são as totais. Nas outras, representam a carga semana.

*Entre parêntesis indicação da paridade.

A licenciatura obtém-se com um mínimo de 155 créditos. 
Plano Curricular aconselhado da Licenciatura em Engenharia Química Disciplinas para 1996/97

\begin{tabular}{|c|c|c|c|c|c|}
\hline \multicolumn{6}{|c|}{$1^{\circ}$ Semestre } \\
\hline \multicolumn{6}{|c|}{ Horas/semana } \\
\hline Disciplina & $\mathbf{T}$ & TP & $\mathbf{P}$ & U.C. & A. C. \\
\hline Álgebra Linear e Geometria Analítica & 3 & 0 & 3 & 4 & Matemática \\
\hline Análise Matemática I & 3 & 0 & 3 & 4 & Matemática \\
\hline Introdução à Química Física & 2 & 0 & 3 & 3 & Química \\
\hline Técnicas de Laboratório & 1 & 1 & 3 & 3 & Química \\
\hline Teoria da Ligação Química & 2 & 2 & 0 & 3.5 & Química \\
\hline \multicolumn{6}{|c|}{$2^{\circ}$ Semestre } \\
\hline Disciplina & $\mathbf{T}$ & TP & $\mathbf{P}$ & U. C. & A. C. \\
\hline Química Inorgânica I & 2 & 0 & 4 & 3.5 & Química \\
\hline Análise Matemática II & 3 & 0 & 3 & 4 & Matemática \\
\hline Introdução Computadores e Programação & 2 & 0 & 2 & 3 & Informática \\
\hline Física I & 3 & 0 & 3 & 4 & Física \\
\hline Química Orgânica AA & 2 & 0 & 4 & 3.5 & Química \\
\hline \multicolumn{6}{|c|}{$3^{\circ}$ Semestre } \\
\hline Disciplina & $\mathbf{T}$ & TP & $\mathbf{P}$ & U.C. & A. C. \\
\hline Física III & 3 & 0 & 3 & 4 & Física \\
\hline Análise Matemática III & 3 & 0 & 3 & 4 & Matemática \\
\hline Química Orgânica AA & 2 & 0 & 4 & 3.5 & Química \\
\hline Opção 1: & & & & & \\
\hline Química Analítica I & 2 & 1 & 2 & 3.5 & Química \\
\hline Métodos Instrumentais de Análise I & 2 & 0 & 3 & 3 & Química \\
\hline \multicolumn{6}{|c|}{$4^{\circ}$ Semestre } \\
\hline Disciplina & $\mathbf{T}$ & TP & $\mathbf{P}$ & U. C. & A. C. \\
\hline Fundamentos dos Processos Químicos & 2 & 0 & 3 & 3 & Eng. Qui. \\
\hline Termodinâmica Química & 3 & 2 & 0 & 4.5 & Química \\
\hline Bioquímica I & 2 & 0 & 4 & 3.5 & Biotecn. \\
\hline Análise Matemática IV & 3 & 0 & 3 & 4 & Matemática \\
\hline Probabilidades e Estatística C & 2 & 0 & 2 & 3 & Matemática \\
\hline \multicolumn{6}{|c|}{$5^{\circ}$ Semestre } \\
\hline Disciplina & $\mathbf{T}$ & TP & $\mathbf{P}$ & U. C. & A. C. \\
\hline Ciências dos Materiais I & 2 & 0 & 3 & 3 & Mat.Inter. \\
\hline Reactores Químicos I & 2 & 0 & 3 & 3 & Eng. Qui. \\
\hline Fenómenos de Transferência & 2 & 0 & 3 & 3 & Eng. Qui.Desenho \\
\hline Industrial & 0 & 2 & 0 & 1.5 & Mat.Inter. \\
\hline Operações Sólido Fluido & 2 & 0 & 4 & 3.5 & Eng. Qui. \\
\hline \multicolumn{6}{|c|}{$6^{\circ}$ Semestre } \\
\hline Disciplina & $\mathbf{T}$ & TP & $\mathbf{P}$ & U.C. & A. C. \\
\hline Química Física II & 2 & 1 & 2 & 3.5 & Química \\
\hline Reactores Químicos II & 2 & 0 & 2 & 3 & Eng. Qui \\
\hline Transferência de Massa e Proces. Separação & 2 & 0 & 3 & 3 & Eng. Qui \\
\hline Computação & 2 & 0 & 3 & 3 & Informática \\
\hline Opção 2 & & & & & \\
\hline
\end{tabular}

\begin{tabular}{|c|c|c|c|c|c|}
\hline \multicolumn{6}{|c|}{$7^{\circ}$ Semestre } \\
\hline Disciplina & $\mathbf{T}$ & TP & $\mathbf{P}$ & U.C. & A. C. \\
\hline Teoria de Sistemas & 2 & 0 & 2 & 3 & Mat. Inter. \\
\hline Engenharia Económica & 3 & 0 & 3 & 4 & Eng. Ind. \\
\hline Processos de Separação I & 2 & 0 & 3 & 3 & Eng. Qui. \\
\hline Reactores Químicos III & 2 & 0 & 3 & 3 & Eng. Qui. \\
\hline Sociologia Industrial & 2 & 0 & 2 & 3 & C.H.S. \\
\hline
\end{tabular}




\begin{tabular}{lccccc}
\hline & $\mathbf{8}^{\mathbf{0}}$ Semestre & & & \\
\hline Disciplina & T & TP & P & U. C. & A. C. \\
Investigação Operacional B & 2 & 0 & 2 & 3 & Eng. Ind. \\
Instrumentação e Controlo & 2 & 0 & 2 & 3 & Eng.Qui. \\
Electrotécnica Geral & 2 & 0 & 2 & 3 & Mat. Int. \\
Planeamento e Controlo de Qualidade & 3 & 0 & 3 & 4 & Eng. Ind. \\
Opção 3 & & & &
\end{tabular}

\begin{tabular}{llclcc}
\hline & $\mathbf{9}$ Semestre & & & \\
\hline Disciplina & T & TP & P & U. C. & A. C. \\
Industrias Químicas & 3 & 0 & 0 & 3 & Eng. Qui. \\
Processos de Separação II & 2 & 0 & 3 & 3 Eng. Qui. \\
Projecto AA & 0 & 3 & 4 & 3.5 & Eng. Qui. \\
Engenharia Bioquímica & 2 & 0 & 4 & 3.5 & Biotecn. \\
Opção 4 & & & & &
\end{tabular}

\begin{tabular}{|c|c|c|c|c|c|}
\hline \multicolumn{6}{|c|}{$10^{\circ}$ Semestre } \\
\hline $\begin{array}{l}\text { Disciplina } \\
\text { Projecto AA } \\
\text { Laboratórios I } \\
\text { Opção } 5\end{array}$ & $\begin{array}{l}\mathbf{T} \\
0 \\
0\end{array}$ & $\begin{array}{l}\text { TP } \\
3 \\
0\end{array}$ & $\begin{array}{c}\mathbf{P} \\
4 \\
10\end{array}$ & $\begin{array}{c}\text { U. C. } \\
3.5 \\
4\end{array}$ & $\begin{array}{l}\text { A. C. } \\
\text { Eng. Qui. } \\
\text { Eng. Qui. }\end{array}$ \\
\hline $\begin{array}{l}\text { Opções *: } \\
\text { Disciplina }\end{array}$ & $\mathbf{T}$ & TP & $\mathbf{P}$ & U. C. & A. C. \\
\hline $\begin{array}{l}\text { História da Ciência (I) } \\
\text { Economia da Empresa (I) } \\
\text { Simulação em Engã. Química (I) } \\
\text { Informação Científica e Técnica (P) } \\
\text { Bioenergética Industrial (P) } \\
\text { Engenharia Genética (P) } \\
\text { Microbiologia (P) } \\
\text { Microbiologia Alimentar (I) } \\
\text { Tecnologia de Enzimas (P) } \\
\text { Tecnologia Microbiana (I) } \\
\text { Análise de Custos Industriais I (I) } \\
\text { Gestão de Stocks I (I) } \\
\text { Métodos Quantitativos (I) } \\
\text { Planeamento e Projecto de Instalações (I) } \\
\text { Gestão Industrial (P) } \\
\text { Energia e Combustão (P) } \\
\text { Ciência de Polímeros (P) } \\
\text { Tecnologia de Plásticos (I) } \\
\text { Petroquímica (P) } \\
\text { Análise de Sistemas e Simul. em Ambiente (I) } \\
\text { Impacte de Projectos no Ambiente (I) } \\
\text { Introdução aos Problemas do Ambiente (I) } \\
\text { Poluição da Água (P) }\end{array}$ & $\begin{array}{l}2 \\
2 \\
2 \\
2 \\
2 \\
2 \\
2 \\
2 \\
2 \\
2 \\
3 \\
3 \\
3 \\
3 \\
2 \\
2.5 \\
2 \\
2 \\
2 \\
2 \\
2 \\
0 \\
2\end{array}$ & $\begin{array}{l}0 \\
0 \\
0 \\
0 \\
0 \\
0 \\
0 \\
0 \\
0 \\
0 \\
0 \\
0 \\
0 \\
0 \\
0 \\
0 \\
0 \\
0 \\
0 \\
0 \\
0 \\
4 \\
0\end{array}$ & $\begin{array}{l}0 \\
3 \\
3 \\
0 \\
4 \\
3 \\
4 \\
4 \\
4 \\
4 \\
3 \\
3 \\
3 \\
3 \\
3 \\
2 \\
0 \\
3 \\
3 \\
3 \\
3 \\
3 \\
0 \\
3\end{array}$ & $\begin{array}{c}2 \\
3 \\
3 \\
2 \\
3.5 \\
3 \\
3.5 \\
3.5 \\
3.5 \\
3.5 \\
4 \\
4 \\
4 \\
4 \\
3 \\
2.5 \\
3 \\
3 \\
3 \\
3 \\
3 \\
2.5 \\
3\end{array}$ & $\begin{array}{l}\text { C. H. S. } \\
\text { C. H. S. } \\
\text { Eng. Qui. } \\
\text { Mat. Int. } \\
\text { Biot./Agroind. } \\
\text { Biot./Agroind. } \\
\text { Biot./Agroind. } \\
\text { Biot./Agroind. } \\
\text { Biot./Agroind. } \\
\text { Biot./Agroind. } \\
\text { Eng. Ind. } \\
\text { Eng. Ind. } \\
\text { Eng. Ind. } \\
\text { Eng. Ind. } \\
\text { Eng. Ind. } \\
\text { Tecn.Util. } \\
\text { Tecn.Util. } \\
\text { Tecn.Util. } \\
\text { Tecn.Util. } \\
\text { Ambiente } \\
\text { Ambiente } \\
\text { Ambiente } \\
\text { Ambiente }\end{array}$ \\
\hline
\end{tabular}




\title{
Uma Sonda Acústica para o Comportamento Crítico ou quase Crítico
}

\author{
A NAI.AGUIAR RICARDO *
}

O mundo que nos rodeia mostra-nos que à temperatura ambiente e pressão atmosférica, existem substâncias no estado sólido, líquido e gasoso. Por outro lado, também é do conhecimento geral que se arrefecermos a água até $0{ }^{\circ} \mathrm{C}$ ela congelará e que pelo contrário, se a aquecermos até $100^{\circ} \mathrm{C}$ entrará em ebulição e vaporizar-se-á. Porém, se a pressão se alterar, as temperaturas a que a água sofrerá estas mudanças de fase serão diferentes. A representação genérica, num gráfico a duas dimensões, das condições de pressão e temperatura a que um composto puro sofre mudanças de fase está representada na fig. 1. Aparecem assim delimitadas pelas linhas de congelamento e de ebulição as regiões das fases sólida, líquida e gasosa. Aparece ainda um ponto único, no qual as três fases podem coexistir na presença umas das outras, que se designa por ponto triplo; no extremo da linha de equilíbrio líquido-vapor surge um ponto, $\mathrm{C}$, de coordenadas (Tc, Pc) que identifica as condições em que as fases líquida e gasosa deixam de ser distinguíveis, e que se designa por "ponto crítico". Surge uma continuidade entre as fases líquida e gasosa e torna-se evidente a possibilidade de construir um trajecto para passar de uma fase à outra sem que para tal haja uma transição de fase brusca.

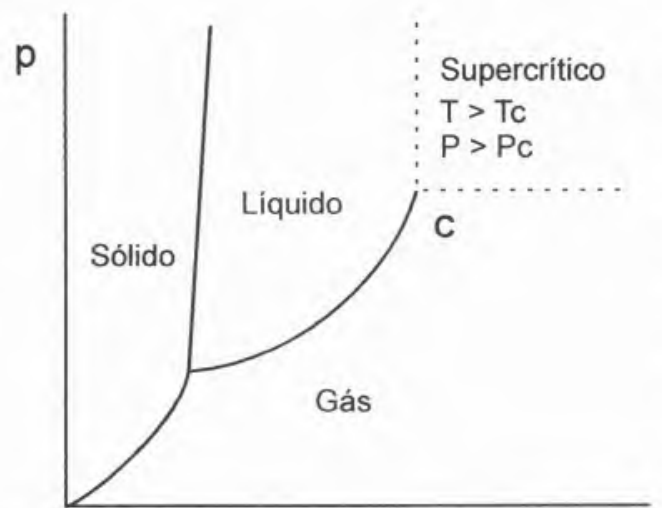

Fig. 1 - Diagrama pressão - temperatura para um composto puro. C é o ponto crítico (definido por $\mathrm{P}(\mathrm{e}$ Tc) onde desaparece a distinção entre as fases liquida e gasosa.
Quando um fluido se encontra nas condições de pressão e temperatura superiores aos valores críticos (zona sombreada na fig.1) diz-se fluido supercrítico. Os fluidos supercríticos apresentam algumas propriedades com valores intermédios entre os de um gás à pressão atmosférica e os de um líquido. Este facto, aliado à sua alta compressibilidade, conferelhes características únicas e possibilita aplicações particularmente interessantes para aquelas substâncias cujo ponto crítico se encontra próximo da temperatura ambiente.

Os fluidos supercríticos têm-se tornado cada vez mais interessantes dada a sua crescente utilização como meios reaccionais e em processos de extracção (1). No entanto, têm-se encontrado alguns obstáculos quando se pretende passar de processos à escala laboratorial para aplicações a nível industrial. Não se pode optar por realizar um dado processo em condições supercríticas só por ser "divertido" e inovador; comercialmente a utilização de meios supercríticos tem de oferecer vantagens reais. Os processos supercríticos estão muitas vezes restritos a áreas apertadas dos diagramas de fase, devido ao comportamento e propriedades do sistema soluto-solvente, o que implica que é necessário um controle muito mais apertado e um dimensionamento mais cuidado dos processos a desenvolver nestes fluidos. Não existem muitos métodos acessíveis para prever com alguma exactidão as propriedades do solvente que se utiliza num dado processo supercrítico. pelo que é premente a necessidade de desenvolver técnicas de determinação de condições críticas.

Infelizmente existem poucas sondas não invasoras para determinar o comportamento de sistemas perto do ponto crítico; em parte, este problema deve-se ao facto da maior parte das propriedades físicas não apresentarem nenhuma variação brusca próximo do ponto crítico. Uma excepção é a compressibilidade isotérmica de um fluido que se torna excepcionalmente grande na vizinhança do ponto crítico, com corres- pondente diminuição da velocidade do som (2). Sabe-se que a compressibilidade isotérmica de um fluido afecta a propagação do som através do fluido. À medida que a compressibilidade aumenta é natural que a propagação do som se torne mais difícil. No ponto crítico a compressibilidade isotérmica (a taxa de variação da densidade com a pressão, a temperatura constante) é infinita e a velocidade do som terá um mínimo absoluto.

A medida de velocidade do som em fluidos supercríticos tem uma longa história. Poderá mesmo dizer-se que a história mais antiga remonta já ao inicio do século passado e se passou com o Barào Cagniard de La Tour que determinou experimentalmente o ponto crítico de um fluido (3).

Sabia-se na época, princípio do séc. XIX, que utilizando a marmita de Papin era possível elevar a temperatura de líquidos muito acima do seu ponto de ebulição normal; o pensamento corrente era que "a compressão interior que aumenta com a temperatura deverá ser um obstáculo à evaporação total do líquido $(. . .)^{\prime \prime}$. O Barão Cagniard de La Tour pensando que apesar desta compressão deveria haver um limite para lá do qual o líquido teria de passar obrigatoriamente para o estado de vapor, realizou a seguinte experiência para verificar esta sua teoria: construiu uma pequena marmita de Papin muito espessa, feita com o cano de uma espingarda; nesta marmita introduziu álcool a $36^{\circ} \mathrm{C}$ e uma esfera de sílex. Foi aquecendo e verificando o barulho que a bola de sílex fazia ao rolar no interior da marmita. Ao atingir determinado ponto, a alteração do som provocado pela esfera levou-o a concluir que não existia qualquer líquido no interior da marmita. Estava assim determinado, pela primeira vez e por medidas acústicas o ponto crítico de um fluido!...

Uma técnica experimental com grandes potencialidades poderá ser uma técnica acústica já que como se explicou acima, assenta na medida de uma propriedade que apresenta 
uma atenuação brusca perto do ponto crítico. As primeiras medidas de propriedades acústicas foram publicadas em 1920 (4) apesar de alguns métodos acústicos terem sido investigados pelo fim do século passado (5). Contudo, a maior parte dos trabalhos desenvolvidos tinha como objectivo a determinação de propriedades termodinâmicas como coeficientes do virial acústicos (6) e não, em particular, parâmetros críticos. Só na década de 80 , é que se iniciou um estudo exaustivo de aplicação de métodos acústicos à medida de parâmetros críticos (7).

Estas experiências pioneiras mostraram que a determinação acústica de parâmetros críticos de substâncias puras não só era possível como permitia uma precisão melhor ou equivalente à conseguida com métodos visuais. Os métodos visuais consideram que se atinge o ponto crítico líquido-vapor quando se dá o desaparecimento do menisco de separação das duas fases. Na vizinhança do ponto crítico a diferença de densidades entre a fase líquida e a fase vapor tende a desaparecer, o que faz com que a determinação das condições em que se dá o desaparecimento do menisco seja influenciada pela subjectividade do experimentador, o que pode conduzir a erros substanciais. Quando se pretendem determinar pontos críticos de sistemas multicomponentes a questão torna-se ainda mais premente.

Na fig. 2 está representada uma sequência de fotografias onde se mostram as observações feitas na determinação visual de um ponto crítico. Para tal utilizou-se uma célula de safira (material transparente e resistente a alta pressão) contendo dióxido de carbono líquido até cerca de $2 / 3$ de altura. A sequência de fotografias foi obtida a temperaturas crescentes da esquerda para a direita; assim, na primeira fotografia, a temperatura é inferior à temperatura crítica e pode observar-se o menisco de separação entre as duas fases líquida e gasosa. Se aumentarmos a temperatura o menisco descerá devido à vaporização de algum dióxido de carbono líquido e tornar-se-á mais ténue até que desaparecerá mesmo. $\mathrm{Na}$ segunda e terceira fotografias a temperatura é próxima da temperatura crítica e aparecem os fenómenos ópticos característicos do ponto crítico. A quarta fotografia, já a uma temperatura ligeiramente superior à temperatura crítica, corresponde ao momento em que se pôs em funcionamento o sistema de agitação do fluido dentro da célula. O alaranjado dispersa-se por toda a célula e desaparece gradualmente como se observa na quinta fotografia (8).

Perante a semelhança entre as fotografias obtidas na vizinhança do ponto crítico apetece certamente perguntar: qual a fotografia que representa realmente o ponto crítico?

Ao contrário do método visual que apresenta as dificuldades que se acabaram de referir, a determinação de um ponto crítico com um método acústico é objectiva e portanto deve fornecer dados com uma precisão superior.

O comportamento acústico de um fluido vai-se alterando consoante as condições de pressão e temperatura a que se encontra e, de uma forma acentuada, quando ocorre uma transição de fase. Quando esta ocorre, a compressibilidade do fluido apresenta uma variação brusca, pelo que a velocidade do som nesse meio sofre também uma alteração significativa.

A maior parte das experiências acústicas descritas na literatura, aplicadas ao estudo de diagramas de fase, são medidas de elevada precisão e a instrumentação envolvida é normalmente muito sofisticada. Quando o objectivo é determinar pontos críticos, o método acústico de medida pode ser consideravelmente simplificado, bastando para tal identificar a região P-T em que a velocidade do som apresenta um mínimo absoluto.

\section{MÉTODO EXPERIMENTAL}

Um método bastante simples e recentemente desenvolvido $(9,10)$ para determinação de pontos críticos
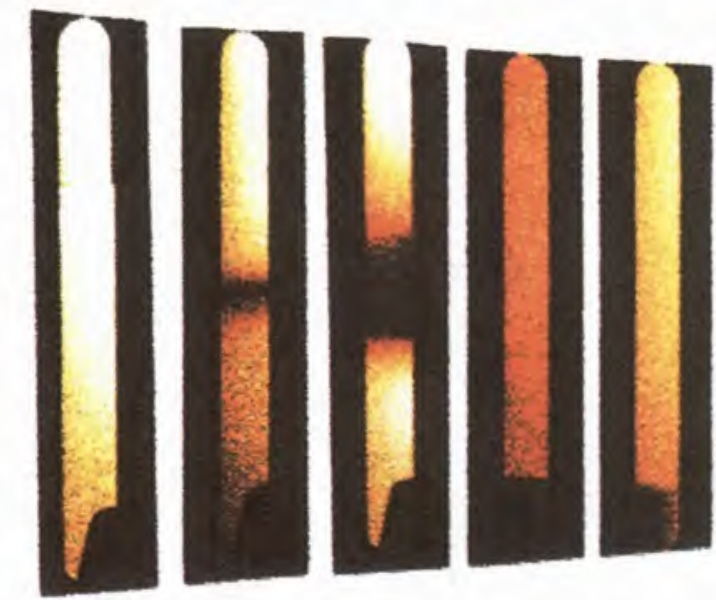

Fig. 2 - Célula de safira contendo dióxido de carbono perto do ponto crítico. A sequência de fotografias foi obtida a temperaturas crescentes da esquerda para a direita. Na segunda e terceira fotografias a temperatura é próxima da temperatura crítica e aparecem os fenómenos ópticos característicos do ponto crítico. A quarta fotografia já a temperatura ligeiramente superior à temperatura critica corresponde ao momento em que se pôs em funcionamento o sistema de agitação do fluido dentro da célula. $O$ alaranjado dispersa-se por toda a célula e desaparece gradualmente como se observa na quinta fotografia. (Reproduzido de Colóquio/Ciências, NÚMERO 16, Fundação Calouste Gulbenkian.)

baseia-se na emissão de um pulso por um microfone (transdutor piezoeléctrico) através da solução, que é detectado por um outro transdutor equivalente que se encontra fisicamente separado da fonte do pulso.

Mede-se o intervalo de tempo necessário para o pulso percorrer a distância que separa os dois transdutores, emissor e receptor; este "tempo de atraso" é inversamente proporcional à velocidade do som no fluido.

\section{Célula e instalação de medidas acústicas}

Introduz-se o fluido que se pretende estudar na célula acústica. A célula é uma cruz de aço inox com um volume interno aproximado de $2 \mathrm{~cm}^{3}$. Em duas posições da cruz diametralmente opostas estão colocados os transdutores, noutra entrada encontra-se o termopar e a quarta posição serve para entrada e saída do fluido. 


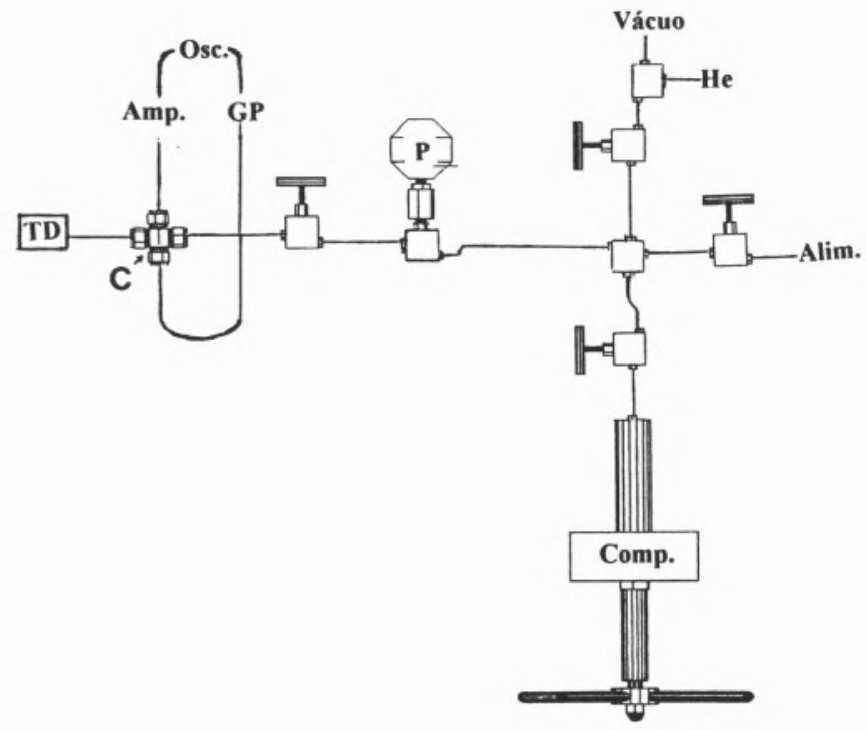

Fig. 3 - Representação esquemática da instalação de medidas acústicas. C - célula acústica; Amp. - amplificador; Comp.- compressor; GP - gerador de pulso; P - indicador de pressão; Osc. - osciloscópio; TD - termómetro digital.
A onda acústica é gerada na célula por aplicação de um pulso de uma certa voltagem, utilizando um gerador de pulsos, a um dos transdutores piezoeléctricos; o segundo transdutor actua como detector/microfone. O sinal acústico recebido por este último é primeiro amplificado e levado então ao osciloscópio. No osciloscópio mede-se o tempo de atraso entre o pulso inicial enviado e o primeiro máximo da resposta acústica.

$\mathrm{Na}$ fig. 3 representa-se esquematicamente a instalação de medidas acústicas e na fig.4 está representado um sinal típico tal como se observa no osciloscópio.

À medida que nos aproximamos da linha de equilíbrio líquido-vapor há uma atenuação da amplitude do sinal e um aumento do atraso. No ponto crítico o intervalo de tempo entre a emissão e recepção da onda acústica é máximo.

\section{Condensação Retrógrada - Um Fenómeno Não Ortodoxo}

A forma das superfícies que representam os diagramas de fases de misturas multicomponentes e as projecções dessas superfícies em espaços a duas dimensões como por exemplo no espaço $(\mathrm{p}, \mathrm{T})$ evidenciam comportamentos inacreditáveis ou no mínimo invulgares para um observador comum.

Estamos habituados à ideia de que seja possível condensar um gás por compressão, mas não nos parecerá nada razoável pensar em obter um gás a partir da compressão de um líquido, ou ainda conseguir obter um líquido aquecendo um gás a uma dada pressão...

Analisemos uma curva (p,T) para uma composição constante como re- presentado na figura abaixo (a). Nesta curva, $\mathrm{A}$ representa o ponto à pressão máxima, $\mathrm{B}$ o ponto à temperatura máxima e $C$ é o ponto crítico que não coincide, como se vê, nem com a má-

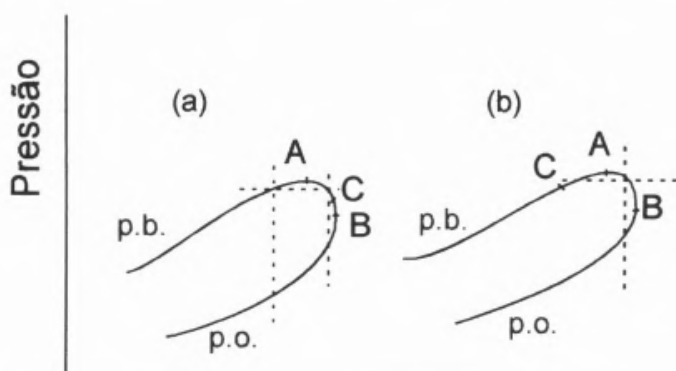

(c)

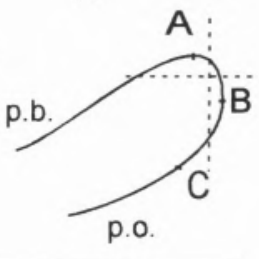

Temperatura 